\title{
A RESPONSABILIDADE COMO PRINCÍPIO ÉTICO EM H. JONAS E E. LEVINAS: UMA APROXIMAÇÃO
}

Evaldo Antonio Kuiava*

SÍNTESE - A responsabilidade enquanto princípio ético, embora seja evocada pelos filósofos clássicos, desde a antiguidade ao existencialismo, assume novas perspectivas a partir do pensamento de Hans Jonas e Levinas. Ambos a colocam como centro da ética. Com Jonas a responsabilidade não é mais centrada no passado e no presente. A sua preocupação é com o futuro da humanidade, com as gerações futuras e com a sobrevivência das mesmas. Diferente de Platão, Jonas não está preocupado com a eternidade, mas com o tempo vindouro, compatível com a era da ciência e da tecnologia, cuja responsabilidade passa a ser o alicerce, o princípio orientador para as decisões que possam interferir nas diferentes formas de vida. Levinas, por sua vez, também se afasta da tradição filosófica na medida em que não aceita mais a tese de que a responsabilidade é decorrente da liberdade. A responsabilidade não nasce de uma boa vontade, de um sujeito autônomo que quer livremente se comprometer com o outro ser. Ela nasce como resposta a um chamado. A responsabilidade é o fundamento primeiro e essencial da estrutura ética, a qual não aparece como suplemento de uma base existencial prévia. Aquém do ser se encontra uma subjetividade capaz de escutar a voz, sem palavras de um dizer original, e aponta para uma outra dimensão do eu. Prévio ao ato de consciência, anterior ao sujeito intencional, o eu já responde a um chamado. A responsabilidade pelo outro ser precede a representação conceitual ou a mediação de um mandamento ético. Ela é obediência a uma vocação, a uma eleição pelo bem além do ser. A responsabilidade determina a
ABSTRACT - Responsibility qua ethical principle, however evoked by classical philosophers from Antiquity through existentialism, assumes new perspectives since the contributions of Hans Jonas and Levinas. Both place it at the center of ethics. With Jonas, responsibility no longer focuses on past and present. His concern is rather with the future of humankind, with future generations and their survival. Contrary to Plato, Jonas is not concerned with eternity, but with the time to come, compatible with the era of science and technology, whose responsibility becomes the groundwork and guiding principle for decisions that might interfere in different life forms. As for Levinas, he also departs from the philosophical tradition insofar as he rejects the thesis that responsibility results from freedom. Responsibility does not stem from a good will, from an autonomous subject who freely wants to be engaged with another being. Responsibility rather emerges as response to a call, it is the first, essential ground of ethical structure, which cannot appear as a supplement of a previous existential basis. Even before Being, one finds a subjectivity capable of listening to a voice, without words, of an originary saying, and points to another dimension of the self. Previous to the act of consciousness, anterior to the intentional subject, the self already responds to the call. Responsibility towards the other being precedes the conceptual representation or the mediation of an ethical commandment. It is obedience to a vocation, to an election by the Good beyond Being. Responsibility determines the freedom of

* Universidade de Caxias do Sul - UCS - eakuiava@hotmail.com

\begin{tabular}{|l|l|l|l|l|r|}
\hline VERITAS & Porto Alegre & v. 51 & n. 2 & Junho 2006 & p. 55-60 \\
\hline
\end{tabular}


A responsabilidade enquanto princípio ético, embora seja evocada pelos filósofos clássicos, desde a antiguidade ao existencialismo, assume novas perspectivas a partir do pensamento de Hans Jonas e Levinas. Ambos a colocam como centro da ética. A partir de Jonas a responsabilidade não é mais centrada no passado e no presente. A sua preocupação é com o futuro da humanidade, com as gerações futuras e com a sobrevivência das mesmas. Diferente de Platão, Jonas não está preocupado com a eternidade, mas com o tempo vindouro, compatível com a era da ciência e da tecnologia, cuja responsabilidade passa a ser o alicerce, o princípio orientador para as decisões que possam interferir nas diferentes formas de vida. Levinas, por sua vez, também se afasta da tradição filosófica na medida em que não aceita mais a tese de que a responsabilidade é decorrente da liberdade. A responsabilidade não nasce de uma boa vontade, de um sujeito autônomo que quer livremente se comprometer com o outro ser. Ela nasce como resposta a um chamado. A responsabilidade é o fundamento primeiro e essencial da estrutura ética, a qual não aparece como suplemento de uma base existencial prévia. Aquém do ser se encontra uma subjetividade capaz de escutar a voz, sem palavras de um dizer original, e aponta para uma outra dimensão do eu. Prévio ao ato de consciência, anterior ao sujeito intencional, o eu já responde a um chamado. A responsabilidade pelo outro ser precede a representação conceitual ou a mediação de um mandamento ético. Ela é obediência a uma vocação, a uma eleição pelo bem além do ser. A responsabilidade determina a liberdade do eu, pois esta não consegue mais se justificar por ela mesma.

Sob o ponto de vista filosófico tradicional, a responsabilidade se constitui como decorrente da liberdade. A noção de responsabilidade é baseada na noção de escolha livre. Uma ação é livre na medida em que se responde por ela. Em princípio, se o ser humano é livre, então cabe a ele assumir as conseqüências dos seus atos. Do contrário não haveria como ser moralmente responsável pelo seu agir. Se as decisões fossem tomadas ao acaso, sob o ponto de vista ético, político e, também, jurídico, haveria a ausência de responsabilidade, nunca haveria culpados. A liberdade de escolha é condição de possibilidade para que o sujeito seja responsável pela sua ação ou omissão. Cabe a cada um responder, diante de si mesmo e diante dos outros, pelo que faz ou pelo que deveria fazer e não fez. Nesse sentido, a responsabilidade exige fundamentalmente a consciência dos atos praticados, a capacidade de entendimento adequado aos princípios éticos. 
Por outro lado, sem responsabilidade não há liberdade. A liberdade depende da responsabilidade que se lhe impõe, como desafio até mesmo para se afirmar como tal. Sem a responsabilidade a liberdade se desvanece, vira libertinagem. Sob o ponto de vista ético o sujeito é responsável quando é capaz de se autodeterminar, quando quer e sabe, isto é, quando tem consciência. O termo consciência refere-se à capacidade de reconhecer que existe algo para além de si. Mas, nesse contexto, ter consciência é ser capaz de reconhecer o bem e o mal, o certo e o errado. Ter consciência ética é ser capaz de escolher e assumir voluntariamente determinadas normas morais, atitudes e posturas éticas diante das mais diversas situações enfrentadas no decorrer da vida pessoal e profissional.

Não há como responsabilizar alguém por aquilo que ele não quis fazer. Uma pessoa é responsável quando inclui nos motivos de sua ação, a previsão dos possíveis efeitos do seu próprio agir. De acordo com o pensamento kantiano, não dá para provar o que a consciência ética de um indivíduo diz, qual é o motivo da sua ação. No entanto, pode-se verificar o que o indivíduo faz. Isso leva a crer que a ética exige que cada um deve agir de acordo com as suas convicções pessoais, mas estas devem estar de acordo com o que é válido para os demais. Embora o conflito faça parte do jogo da sociedade, e preciso saber discernir o que é moralmente justo para si e para a sociedade, assumindo sempre a conseqüência dos atos praticados.

Desse modo, sob o ponto de vista da gestão pública, a responsabilidade pode ser entendida como capacidade que o gestor público tem de sentir-se comprometido a responder ou cumprir uma tarefa que é sua sem qualquer pressão externa à sua consciência ética. O gestor público responsável toma suas decisões, faz o que precisa ser feito, sem ficar esperando que alguém lhe dê ordens ou lhe faça qualquer tipo de cobrança. Exige-se ainda de todo e qualquer profissional e, especialmente, do gestor público, que saiba lidar conscientemente com as conseqüências dos atos praticados. Nesse sentido, ser responsável é ser capaz de prever os efeitos do próprio comportamento e quando for equivocado saber corrigir com base em tal previsão. Exige-se do gestor público a capacidade de influir e intervir nas decisões que envolvem a coletividade, tendo sempre em vista o bem comum. Bem comum, de acordo com Martini (1994, p. 31-32), "é o conjunto das condições de vida de uma sociedade que favorecem o bem-estar e o progresso humano de todos os cidadãos".

Cabe destacar que a responsabilidade enquanto princípio ético, embora seja evocada pelos filósofos clássicos, desde a antigüidade até o existencialismo, assume novas perspectivas a partir do pensamento de Hans Jonas e Levinas (filósofos do séc. XX). Ambos os autores a colocam como centro da ética.

Com Jonas a responsabilidade não é mais centrada no passado e no presente. A sua preocupação e com o futuro da humanidade, com as gerações futuras e com a sobrevivência das mesmas. Diferente de Platão, Jonas não está preocupado com a eternidade, mas com o tempo vindouro, compatível com os tempos atuais, com a era da ciência e da tecnologia, cuja responsabilidade passa a ser o alicerce, o princípio orientador para as decisões que possam interferir nas diferentes formas de vida. 
Sob o ponto de vista da política essa visão exige um comprometimento maior com as gerações atuais e também com as futuras. Nesse caso, a questão essencial da responsabilidade do gestor público ou do político é exercer o poder para os outros e não um poder sobre os outros. Todas as políticas públicas devem ter essa postura como premissa básica para que se possa garantir o futuro da humanidade. Jonas formula um novo imperativo, um princípio ético para que cada agente da sociedade possa guiar-se no exercício da cidadania. Veja a formulação:

Age de maneira tal que os efeitos de tua ação sejam compatíveis com a permanência de autêntica vida humana sobre a terra; ou: age de maneira tal que os efeitos de tua ação não sejam destrutivos da possibilidade de autêntica vida humana futura na terra. Ou, não ponhas em perigo as condições da continuidade indefinida da humanidade na terra; ou: inclui na tua opção presente, como objeto também de teu querer, a futura integridade do homem (1995, p. 40).

Ninguém está legitimado ou autorizado sob o ponto de vista ético colocar em risco o futuro dos cidadãos em prol de benefícios próprios. O princípio ético proposto por Jonas está voltado ao domínio da política pública e não somente ao agir privado de cada agente social. Nesse caso, tendo como referência o imperativo proposto, mister se faz, no campo da gestão pública, criar projetos difusores da justiça social em que a dimensão da ética seja incorporada ao lado dos saberes técnicos ou legais para o favorecimento de todos. O princípio da responsabilidade de Jonas, nesse sentido, é uma orientação para uma política responsável. Trata-se de um convite a cada ser humano para ampliar os horizontes da ética e da política e ajude a construir um mundo mais humano para todos.

A responsabilidade também pode ser entendida como condição de possibilidade para tornar a liberdade justa. Ou seja, a liberdade precisa se justificar sob o ponto de vista da justiça social. Essa tese é defendida por Levinas. A razão e a liberdade fundadas no sentido originário desenham uma estrutura cujas primeiras articulações são de respeito e justiça em relação ao outro. "Justificar a liberdade não é demonstrá-la, mas torná-la justa”, afirma Levinas na sua obra Totalidade e Infinito (1988, p. 70). Na sua visão, mostrar a um indivíduo tal orientação é identificá-lo com a ética. O eu perante o outro é infinitamente responsável.

A responsabilidade não nasce de uma boa vontade, de um eu que quer se comprometer com o outro. A responsabilidade nasce como resposta. Ela caracteriza e identifica o sujeito ético como único e imediatamente para-o-outro. A responsabilidade é o existencial primeiro, a estrutura básica da racionalidade humana, do universo verdadeiramente humano. Levinas, ao descrever a estrutura ética da racionalidade, coloca como fundamento primeiro e essencial, a responsabilidade. A ética não aparece como suplemento de uma base existencial prévia, mas como responsabilidade que brota da subjetividade humana. Aquém do ser se encontra uma subjetividade capaz de escutar a voz, sem palavras de um dizer original, e que aponta para uma outra dimensão do eu. Prévio ao ato de consciência, anterior ao sujeito intencional, o eu já responde a um chamado. A responsabilidade pelo outro ser prescinde da representação conceitual ou da 
mediação de um mandamento ético. Ela é obediência a uma vocação, a uma eleição pelo bem além do ser. A responsabilidade determina a liberdade do eu. A liberdade não consegue se justificar por ela mesma. A infinitude não está no livre arbítrio, mas na responsabilidade pelo outro homem.

A moralidade, para Levinas, não se funda sobre a autonomia da vontade racional, mas, sobre uma outra base que orienta e precede o sujeito, ordenandolhe o bem. Isso não significa, que a partir da autonomia da vontade, o eu seja incapaz de realizar ações de cunho ético, mas uma ética que tem como base a consciência que coincide consigo mesma não assegura o respeito ao outro ser. Não se trata aqui de negar a identidade do eu, mas de afirmar a individualidade do sujeito, a partir da responsabilidade por outrem. O eu é incumbido da responsabilidade, com exclusividade, e a qual não pode humanamente recusar. O eu é, na medida em que é responsável por outrem. Ele pode substituir a todos, mas ninguém pode substituí-lo. Essa é a sua identidade inalienável de sujeito. Desse modo, pode afirmar-se que a responsabilidade individua o eu, pois ninguém pode assumir no seu lugar essa condição.

Para expressar o alcance dessas premissas, Levinas cita uma frase conhecida de Dostoievsky: "Somos todos culpados de tudo e de todos perante todos, e eu mais do que os outros" (1982, p. 105). A responsabilidade do eu é infinita. Ele é responsável, não só pelos atos ilícitos que comete, mas também por aqueles que não são de sua autoria, e até mesmo pelas perseguições que sofre. Como justificar tal concepção utópica? Não seria ela inumana? Eis a resposta de Levinas: "Ser humano significa: viver como se não se fosse um ser entre os seres. Como se, pela espiritualidade humana, se invertessem as categorias do ser, em um 'de outro modo que ser'" (1982, p. 107). O humano emerge, quando o eu, ao invés de procurar satisfazer seus interesses, estende a mão a outrem, carregando o peso do mundo nos seus próprios ombros.

A manifestação do humano acontece, quando o eu prefere a injustiça sofrida à injustiça cometida. O caráter humano de um sujeito não se dissocia da responsabilidade por outrem. O desafio para o ser humano é deixar que ela ultrapasse os limites da sua liberdade de poder decidir ou não em favor de outrem. Isso significa que a responsabilidade é ilimitada, em oposição a uma responsabilidade, que se mede pelos compromissos livres de uma consciência egoísta. Ser humano é responder a uma eleição anteriormente ao ato de consciência. Sob o ponto de vista político a responsabilidade exprime o caráter pelo qual um determinado governante ou gestor público age sob controle dos cidadãos e em função deste controle. 


\section{Referências}

ARISTOTELES. Ética a Nicômaco. São Paulo: Nova Cultural, 1987. Vol. II. Coleção os pensadores. (EN). BERTEN, André. Filosofia Política. São Paulo: Paulus, 2004.

ESPINOSA, Baruch de. Ética. São Paulo: Nova Cultural, 1989.

HEGEL, G. W. F. Principios de la filosofía del Derecho o Derecho Natural y Ciencia Política. Buenos Aires: Editorial Sudamericana, 1975.

JONAS, Hans. El principio de responsabilidad. Ensayo de una ética para la civilización tecnológica. Barcelona: Herder, 1995.

KANT, Immanuel. Crítica da Razão Pura. Trad. Valério Rohden e Udo Moosburger. São Paulo: Abril Cultural, 1980. 2v. (B).

(BA)

. Fundamentação da Metafísica do Costumes. Trad. Paulo Quintino. Lisboa: Edições 70, 1991.

KUIAVA, Evaldo Antônio. Subjetividade transcendental e alteridade: um estudo sobre a questão do outro em Kant e Levinas. Caxias do Sul, EDUCS, 2003

LEVINAS, Emmanuel. Totalidade e Infinito. Trad. José P. Ribeiro. Lisboa: Edições 70, 1988.

Humanisme de l'autre homme. Montpellier: Fata Morgana, 1972

Éthique et Infini. Dialogues avec Philippe Nemo. Paris: Librairie Arthème Fayard et RadioFrance, 1982

OLIVEIRA, Manfredo Araújo de. Ética e Práxis Histórica. São Paulo: Ática, 1995.

Ética e sociabilidade. São Paulo: Loyola, 1993.

PIVATTO, Pergentino S. (Org.) Ética: Crise \& perspectivas. Porto Alegre: EDIPUCS, 2004.

PIZZI, Jovino. Ética e responsabilidade social. Pelotas: EDUCAT, 2004.

SARTRE, Jean-Paul. O existencialismo é um humanismo. 3ª ed. São Paulo: Nova Cultural, 1987.

SOUZA, Ricardo Timm de. Ética como Fundamento: Uma introdução à ética contemporânea. São Leopoldo: Nova Harmonia, 2004.

VAZ, H. C., de Lima. Escritos de filosofia IV: Introdução à ética filosófica I. São Paulo: Loyola, 1999.

WEIL, Eric. Filosofia Política. São Paulo: Loyola, 1990. 